\title{
Poison Control Centers on the Chopping Block-Will This Affect the Training of Future Medical Toxicology Fellows?
}

\author{
David H. Jang
}

Published online: 17 June 2010

(C) American College of Medical Toxicology 2010

One of the issues potentially facing the subspecialty of medical toxicology is the decreasing number of poison control centers in the country. Most poison centers currently rely on a combination of federal, state, and local funding [1, 2]. While the current economic crisis has affected many poison centers, concerns about the stability of funding apply to most current poison centers. This is a complex topic that has directly affected many poison centers across the country. For example, in the state of California, in May 2009 , there was a proposal to cut all funding to poison centers in an attempt to balance the state budget. This potentially would have resulted in a state-wide closure of all poison centers in the state of California. Fortunately, due to the efforts of many groups, half of the budget was preserved with the remaining amount matched by other funding. In the state of Washington, a substantial portion of the poison center funding was cut, resulting in the cutting of a majority of its outreach programs. Their decreased ability to maintain awareness with poisonings may be associated with their subsequent decrease in call volume. While there are 60 poison centers receiving more than four million calls annually, many are at risk for closure [3]. This may be relevant to our specialty, in particular for those

Editor's Note: The Editorial Board of the Journal of Medical Toxicology (JMT) is pleased to announce the appointment of a new Fellow in Training (FIT) Member, Dr. David H. Jang. Dr. Jang is a first-year FIT at the New York City Poison Center and New York University. He will be responsible for a new opinion/editorial section, entitled, "The Fellows' Perspective". The opinions stated in this section are those of the author and do not necessarily reflect the opinions of JMT or the American College of Medical Toxicology (ACMT).

D. H. Jang $(\bowtie)$

New York University/New York City

Poison Control Center, New York, USA

e-mail: Jangd01@nyumc.org fellowships that have a significant interaction with their poison centers.

Medical toxicology fellowships vary in their interaction with their poison centers. I have spoken to other fellowsin-training who have little interaction with their poison centers whereas there are those who maintain a close relationship. I am currently at a fellowship where we are actively involved in the day-to-day activities of our poison center. While we serve as medical consultants for the Certified Specialists in Poison Information (CSPIs), I also occasionally "moonlight" answering phone calls we receive from the public as well as other health care providers. This experience has given me insight into the importance of poison centers and the complex job of the CSPI.

My experience answering calls serves to illustrate some of the important functions of poison centers. I have received calls from frantic parents about an unintentional ingestion of a dreaded "silica gel" packet, in which the "skull and crossbones" labeling equate ingestion of this benign product with that of cyanide. I have helped to educate the parents about nontoxic exposure as well as prevent needless calls to 911 and visits to the emergency department, which no doubt would happen if poison center services were not available. It is estimated that over $80 \%$ of callers to poison centers are managed at home without ever having to visit the hospital. This no doubt results in savings in health care costs [4].

Poison centers are at the forefront of providing medical information to both health care providers as well as the general public. They are available $24 \mathrm{~h}$ a day and 7 days a week and they fulfill a variety of other functions. Several studies have demonstrated the savings poison centers provide. It is estimated that every dollar spent on poison centers results in a seven dollar savings in health care costs [3]. Poison centers also monitor for potential outbreaks of 
poisoning and alerting the public health infrastructure. The American Association of Poison Control Centers, which is a private nongovernmental association representing the US poison centers, maintains the National Poison Data System (NPDS). The NPDS is a large database holding information from human poison exposure cases that are called into all poison centers across the country. This database documents data in real time which has allowed identification of poison outbreaks by clinicians. This database also serves as a mechanism to track these events when they occur [5].

While I do believe that the interaction between the poison centers and medical toxicology is no doubt beneficial, I also think this specialty will continue to grow despite the decreasing number of poison centers. There are many other ways our specialty continues to expand aside from just acting as a medical director or a medical support staff for a poison center [6]. Medical toxicologists have identified epidemics, perform groundbreaking research, and are involved with terrorism preparedness to name a few. With regard to a reporting system, the American College of Medical Toxicology (ACMT) has launched a database of poison exposure called Toxicology Investigators' Consortium (ToxIC). Currently, including over 60 sites, it is in the process of developing a patient registry of human cases for whom care was directly provided at the bedside. There are many advantages ToxIC may have over the NPDS. Not only will this allow retrospective studies, the information directly obtained at the bedside will no doubt be more accurate and comprehensive compared to what could be obtained by consultations done by the phone. The potential that ToxIC provides is vast that includes but is not limited to research, having a better understanding of various practices, and monitoring for outbreak or poisoning patterns. Not only will this give strength to our specialty but allow potential collaboration with other specialties.

In summary, my interaction with the poison centers has served to broaden my own growth and development during fellowship. The poison centers do serve an important service not only to the general public but also other health care providers who may not have extensive exposure to the field of medical toxicology. Let's face it...people do scary things out there (I'll save my story of a small ED who routinely give naloxone and flumazenil after intubating obtunded overdose patients for another time).

Acknowledgments The author would like to thank Robert Hoffman, $\mathrm{MD}$ and Lewis Nelson, MD for their kind review.

\section{References}

1. Giffin S, Heard SE (2009) Budget cuts and U.S. poison centersregional challenges create a nationwide problem. Clin Toxicol 47:790-791

2. Thompson CA (2009) Poison control centers suffer state budget cuts. Am J Health Syst Pharm 66:1682

3. Artalego L, Crouch B, Geller RJ et al (2008) The value of the poison control center. http://www.aapcc.org. Accessed May 28, 2010

4. Krenzelok EP (2001) Poison information centers save lives... and money! Przegl Lek 58:175-176

5. Hayes BD, Anderson BD (2009) Twenty five years of poison center experience with propoxyphene overdoses the FDA could not find. Clin Toxicol 47:905-906

6. White SR, Baker B, Baum CR et al (2010) 2007 survey of medical toxicology practice. J Med Toxicol (in press) 